\title{
Functionally Graded Coating for Steels by Reaction Diffusion Using $\mathrm{FeAl}_{3}$ Powder
}

\author{
Y. TSUCHIDA, S. KIRIHARA and Y. TOMOTA ${ }^{11}$ \\ Graduate student of Ibaraki University, 4-12-1 Nakanarusawa, Hitachi, Ibaraki 316-8511 Japan. \\ 1) Department of Materials Science, Faculty of Engineering, Ibaraki University, 4-12-1 Nakanarusawa, Hitachi, Ibaraki $316-8511$ \\ Japan.
}

(Received on April 11, 2000; accepted in final form on June 14, 2000)

\begin{abstract}
The powder liquid coating method has successfully been applied to a commercially available pure iron and a carbon steel (JIS-S45C) using $\mathrm{FeAl}_{3}$ powder. The coated layer is found well graded in terms of microstructure, chemical compositions and hardness, so that the coated layer is much stronger for thermal shock than that made by a conventional aluminizing method. Changes in the graded microstructure during coating procedures are studied; it is noted that an $\mathrm{FeAl} / \mathrm{FeAl} \mathrm{F}_{2}$ eutectoid structure formed in the coated layer shows $927 \mathrm{HV}$ and relatively high toughness. Although the present coating technique needs to heat a sample up to an elevated temperature as high as $1473 \mathrm{~K}$, the prior austenite grain size of the carbon steel was refined by so-called Grange method, without accompanying any serious damages in the coated layer.
\end{abstract}

KEY WORDS: functionally graded coating; powder-liquid coating; steel; FeAl ${ }_{3}$; thermal shock; Grange method.

\section{Introduction}

$\mathrm{Fe}-\mathrm{Al}$ intermetallic compounds like $\mathrm{Fe}_{3} \mathrm{Al}$ have been known to exhibit high resistance to corrosion, oxidation and wear, ${ }^{1)}$ so that even stainless steels or nickel based alloys are sometimes coated by aluminizing. ${ }^{2)}$ A drawback of the aluminizing is that the coated layer is easily fractured or peeled off by thermal shock. In general, the brittleness is a common drawback for intermetallic compounds to be overcome. Our idea is to use such a brittle intermetallic compound by introducing functionally graded structure. We have proposed that the functionally graded coating can be easily made for $\mathrm{Ti}$ by using intermetallic compound powder. $^{3-6)}$ When we find a eutectic reaction in a phase diagram, we can use the powder-eutectic coating method ${ }^{3)}$ where liquid phase is yielded between a metal and an intermetallic compound accompanying endothermic reaction. On the other hand, when we find a peritectic reaction in a phase diagram, we can employ the powder-liquid coating accompanying exothermic reaction. ${ }^{5)}$ The $\mathrm{Fe}-\mathrm{Al}$ binary system contains peritectic reactions. ${ }^{7}$ Hence, the powderliquid coating method may be applicable to iron and steel using an appropriate aluminide. In this investigation, we chose $\mathrm{FeAl}_{3}$ for powder, and a pure iron and a carbon steel (JIS-S45C) for substrates. It would be very attractive from the ecomaterial point of view if a carbon steel can be used instead of a stainless steel by coating with $\mathrm{Fe}-\mathrm{Al}$ intermetallics.

\section{Experimental Procedures}

Button-ingots of the stoichiometric $\mathrm{FeAl}_{3}$ intermetallic compound were made by arc-melting in an Ar gas atmosphere and crushed down to powder with less than $63 \mu \mathrm{m}$ in diameter. Substrates with $8 \times 8 \times 3 \mathrm{~mm}$ were made using a commercial pure-Fe $(99.8$ mass $\% \mathrm{Fe})$ and a carbon steel, JIS-S45C (0.45C, 0.24Si, 0.76Mn, 0.021P, 0.018S, 0.01Cu, $0.02 \mathrm{Ni}, 0.13 \mathrm{Cr}$ in mass $\%$ ). A solvent was prepared by mixing $5 \mathrm{~g}\left(\mathrm{KPO}_{3}\right) \mathrm{n}, 2.0 \mathrm{~g}\left(\mathrm{NaPO}_{3}\right)_{6}$ and $1000 \mathrm{ml}$ water. ${ }^{8)}$ The surface of a substrate was pasted with the $\mathrm{FeAl}_{3}$ powder which was mixed with the solvent. Then, the substrates were heated at $1473 \mathrm{~K}$ for $300 \mathrm{~s}$ followed by furnace cooling at a rate of approximately $0.083 \mathrm{~K} / \mathrm{s}$ in an $\mathrm{Ar}$ gas atmosphere (specimens FGC-1 and FGC-2, see Table 1). To control the microstructure of the $\mathrm{S} 45 \mathrm{C}$ substrate during powder-liquid coating process, the substrate was coated at $1473 \mathrm{~K}$ for $300 \mathrm{~s}$ followed by furnace cooling to $1123 \mathrm{~K}$, then quenched into water and tempered at $873 \mathrm{~K}$ for $3.6 \mathrm{ks}$ (specimen FGC-3). Semi-round bar specimens were also made using $\mathrm{S} 45 \mathrm{C}$ and their surfaces were coated by the same procedure with FGC-3 specimen (specimen FGC-4).

To compare this technique with one of conventional aluminizing methods, i.e., aluminum pack cementation, ${ }^{8)} \mathrm{S} 45 \mathrm{C}$ substrates were embedded in a mixture of $\mathrm{Al}, \mathrm{AlCl}_{3}$, and $\mathrm{Al}_{2} \mathrm{O}_{3}$ powders $(20: 5: 75$ by mass percent ratio) and heated at $1173 \mathrm{~K}$ for $21.6 \mathrm{ks}$ followed by furnace cooling (specimen Pack-1). All specimens made in this study are tabulated in Table 1.

Hardness in a coated layer was measured by a Vickers hardness tester with a load of $50 \mathrm{~g}$, where indentations were 
Table 1. Specimen, substrate, and coating conditions.

\begin{tabular}{|l|l|l|}
\hline Specimen & \multicolumn{1}{|c|}{ Substrate } & \multicolumn{1}{c|}{ Coating condition } \\
\hline FGC-1 & Pure Fe, plate & $1473 \mathrm{~K}, 300 \mathrm{~s} \rightarrow$ furnace cooling to RT \\
\hline FGC-2 & S45C, plate & $1473 \mathrm{~K}, 300 \mathrm{~s} \rightarrow$ furnace cooling to RT \\
\hline FGC-3 & S45C, plate & $\begin{array}{l}1473 \mathrm{~K}, 300 \mathrm{~s} \rightarrow \text { furnace cooling to 1123K } \\
\rightarrow \text { quenching into water(RT) } \rightarrow \text { tempering } \\
\text { at } 873 \mathrm{~K} \text { for } 3.6 \mathrm{ks}\end{array}$ \\
\hline FGC-4 & S45C, semi-round bar & $\begin{array}{l}1473 \mathrm{~K}, 300 \mathrm{~s} \rightarrow \text { furnace cooling to 1123K } \\
\text { quenching into water(RT) } \rightarrow \text { tempering } \\
\text { at } 873 \mathrm{~K} \text { for } 3.6 \mathrm{ks}\end{array}$ \\
\hline Pack-1 & S45C, plate & $1173 \mathrm{~K}, 21.6 \mathrm{Ks} \rightarrow$ furnace cooling to RT \\
\hline
\end{tabular}

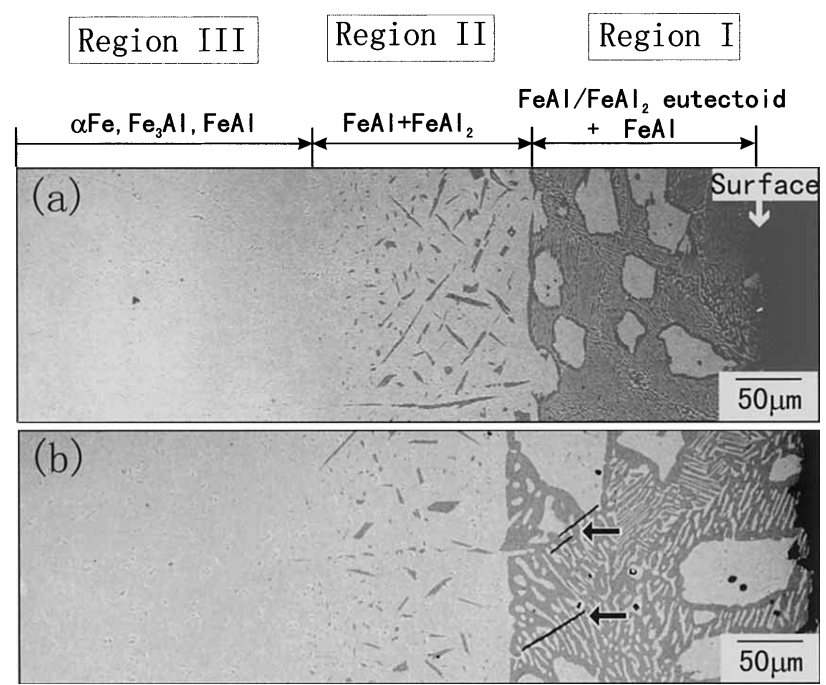

Fig. 1. SEM micrographs of coated layers for FGC-1 specimen (a) and FGC-2 specimen (b).

made from the free surface towards the substrate with an interval of $50 \mu \mathrm{m}$. Microstructures were observed using SEM with BEI mode in the cross section of a specimen.

Thermal shock resistance was evaluated by repetition of heating and cooling with a rate of approximately $20 \mathrm{~K} / \mathrm{s}$ between $873 \mathrm{~K}$ and room temperature for FGC-2, FGC-3 and Pack-1 specimens. This thermal cycle was repeated 200 times.

\section{Experimental Results}

\subsection{Microstructures of FGC-1 and FGC-2 Specimens}

SEM micrographs obtained from FGC-1 and FGC-2 specimens are shown in Fig. 1. As seen, the microstructure in a region near the free surface of the coated layer in FGC1 specimen (region I) consists of $\mathrm{FeAl} / \mathrm{FeAl}_{2}$ eutectoid structure and coarse $\mathrm{FeAl}$ grains. The thickness of the region is approximately $180 \mu \mathrm{m}$. In the second region (region II) in Fig. 1(a), $\mathrm{FeAl}_{2}$ precipitates are distributed in the FeAl matrix. Then, in the third region (region III), a mixture of $\mathrm{FeAl}, \mathrm{Fe}_{3} \mathrm{Al}$, and ferrite $(\alpha \mathrm{Fe})$ is found between the region II and the $\alpha \mathrm{Fe}$ substrate. Such $\mathrm{Fe}-\mathrm{Al}$ intermetallics were identified by X-ray diffraction by polishing away the surface of the specimen repeatedly. The appearance of these intermetallic compounds is almost consistent with the prediction from the phase diagram ${ }^{7)}$ (see Fig. 8 to appear in Sec. 4.1). The microstructural evolution in the coating layer upon heating and cooling will be discussed in Sec. 4.1.

In the case of $\mathrm{S} 45 \mathrm{C}$ substrate (FGC-2 specimen) shown in Fig. 1(b), the microstructure was similar to that of FGC1 except the intrusion of precipitates which were indicated

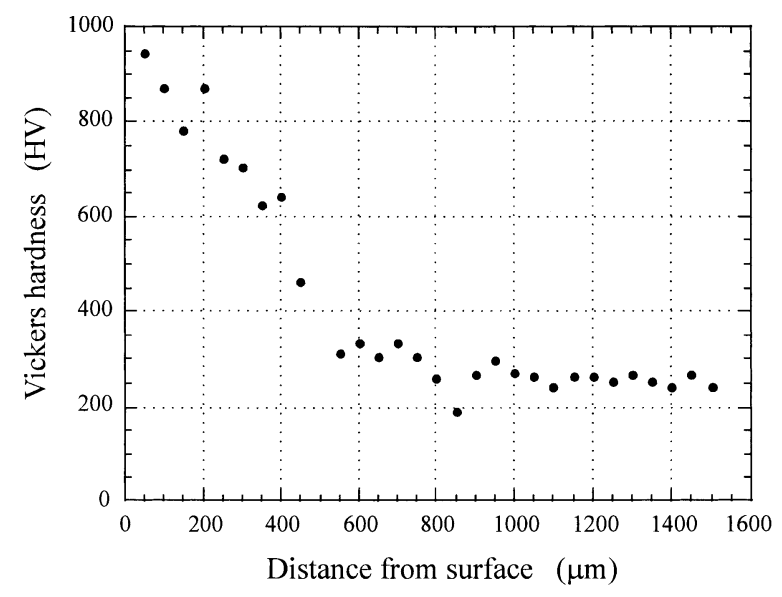

Fig. 2. Hardness distribution for a cross section of FGC-3 specimen.

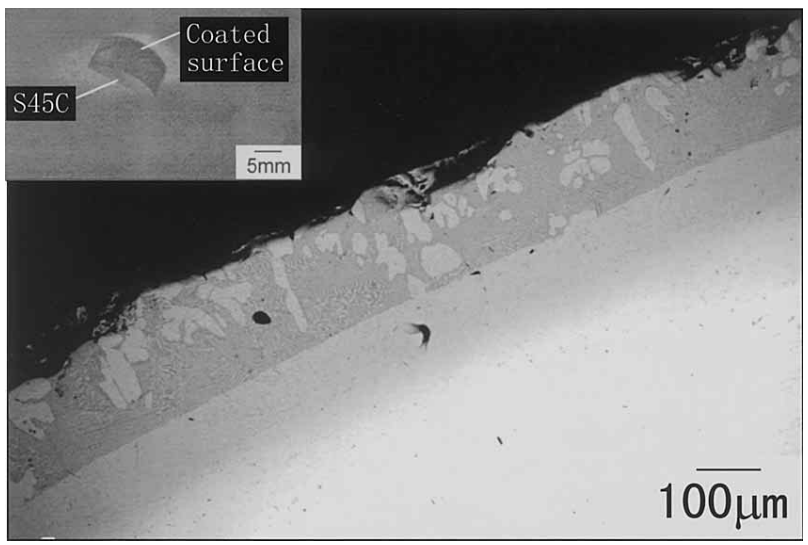

Fig. 3. SEM micrograph of coated layer for FGC-4 specimen in which the overall aspect of a specimen is inserted.

by arrows. These precipitates are speculated to be carbide.

\subsection{Hardness Distribution in a Coated Layer of FGC- 3 Specimen}

Figure 2 shows the hardness distribution in the coated layer of FGC-3 specimen which was quenched and tempered after the coating. As seen, the hardness near the free surface was as high as $900 \mathrm{HV}$ which was obtained for $\mathrm{FeAl} / \mathrm{FeAl}_{2}$ eutectoid structure. Hardness was decreased gradually with increasing the distance from the surface and reached the hardness of the substrate, $240 \mathrm{HV}$, at about 800 $\mu \mathrm{m}$.

\subsection{Coating of a Semi-round Bar Specimen (FGC-4 Specimen)}

To examine the applicability of this technique to near net shaped samples, a semi-round bar made of S45C was prepared and coated with $\mathrm{FeAl}_{3}$ powder. The microstructure at 

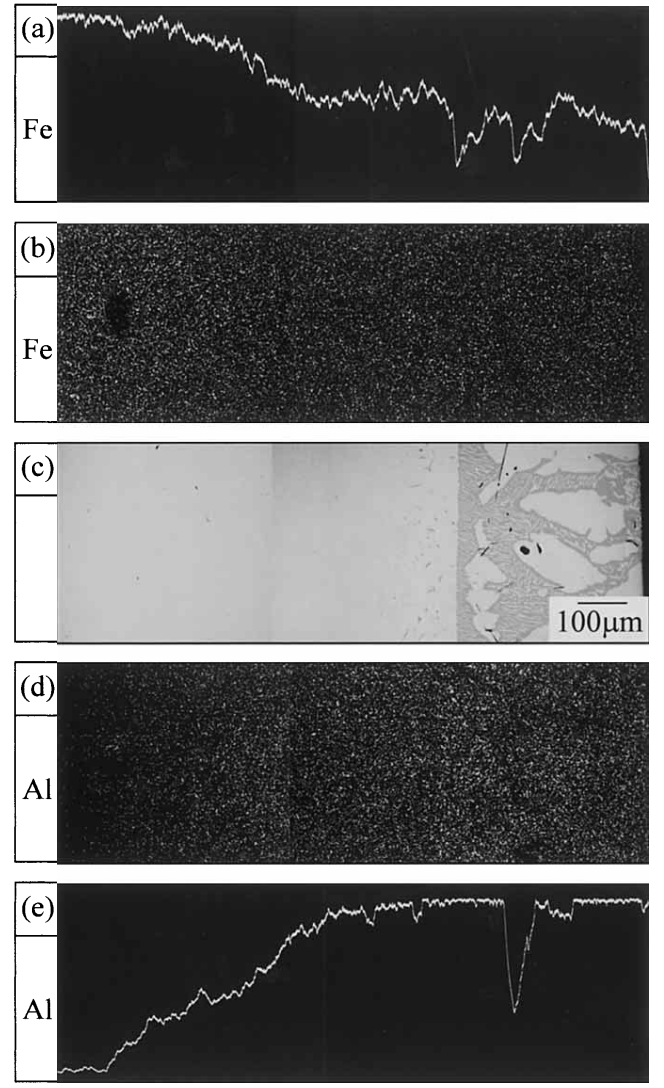

Fig. 4. Depth profiles and dot maps for the cross section of FGC-2 specimen: (a) EDX line analysis for $\mathrm{Fe}$, (b) area analysis for $\mathrm{Fe}$, (c) SEM microstructure, (d) area analysis for $\mathrm{Al}$ and (e) line analysis for $\mathrm{Al}$.

the cross section of the specimen is shown in Fig. 3. It is found that the coated layer is similar to that of the plate specimen shown in Fig. 1(b). The coated layer was uniform, suggesting that this technique is applicable to real mechanical parts.

\subsection{Concentration Profiles of Fe and Al Examined by EDX}

The concentrations of $\mathrm{Fe}$ and $\mathrm{Al}$ in the coated layers were examined by using EDX for FGC-2 and Pack-1 specimens. Depth profiles and dot maps for FGC-2 specimen are presented in Fig. 4. As seen, with increasing the distance from the surface towards the substrate, Al concentration is decreased gradually while $\mathrm{Fe}$ concentration is increased. The changes in their concentrations are gradual. Aluminum atoms are found to diffuse into the substrate approximately $1 \mathrm{~mm}$ from the surface, which corresponds to the hardness distribution found in Fig. 2. Consequently, FGC-2 specimen showed excellently graded characteristics not only in its microstructure, but also in chemical composition and hardness.

Here, the present results are compared with those of a specimen prepared by the conventional aluminizing method (Pack-1 specimen). As shown in Fig. 5, a large difference is found in the concentration profiles of $\mathrm{Al}$ and $\mathrm{Fe}$ compared with FGC-2 specimen (see Fig. 4). The surface layer consisted of $\mathrm{FeAl}_{3}$ showing a very narrow graded region towards the substrate. The chemical compositions changed drastically. Such a feature is commonly observed in commercially aluminized products. ${ }^{10)}$
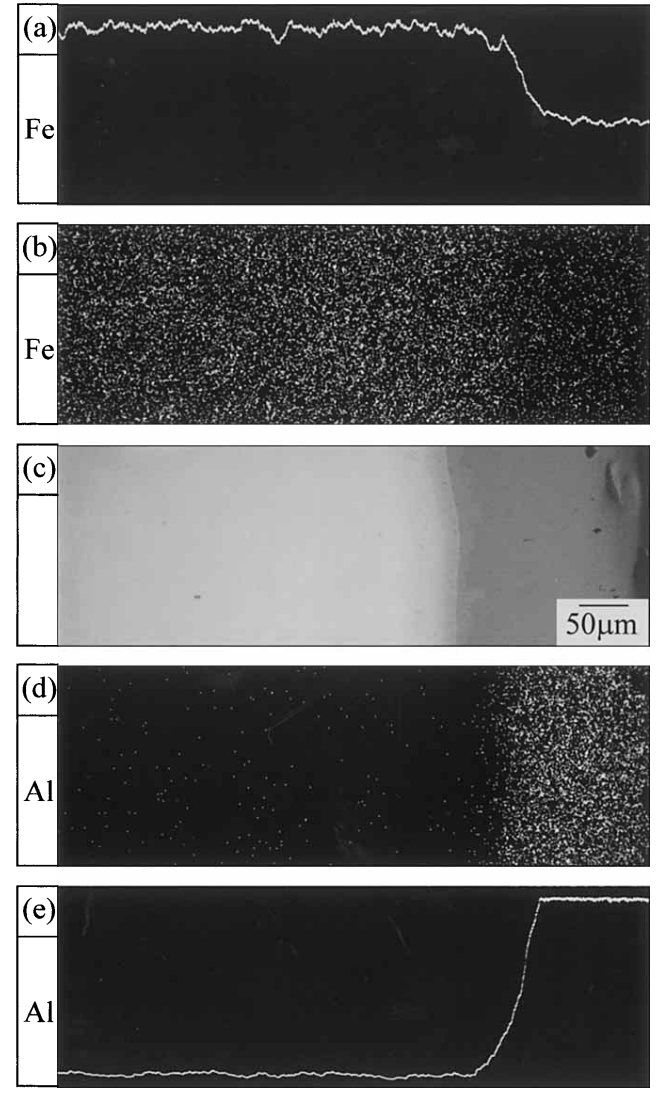

Fig. 5. Depth profiles and dot maps for the cross section of Pack-1 specimen: (a) EDX line analysis for Fe, (b) area analysis for $\mathrm{Fe}$, (c) SEM microstructure, (d) area analysis for $\mathrm{Al}$ and (e) line analysis for $\mathrm{Al}$.

\subsection{Results of Cyclic Heating and Cooling Test}

Thermal shock resistance of FGC-2, FGC-3 and Pack-1 specimens was examined by the thermal cycles of 200 times. Microstructures in the cross sections of FGC-3 specimen and Pack-1 specimen before and after testing are compared in Fig. 6. In FGC-3 specimen, neither cracks nor defects were visible after the test and the thickness and microstructure of the coated layer were scarcely changed by cyclic heating (see Fig. 6(b)). The results of FGC-2 specimen were similar to those of FGC-3 specimen. On the other hand, in Pack-1 specimen, the thickness of the coated layer decreased after testing (compare (d) with (c)). The thinning of the coated layer is caused by diffusion of $\mathrm{Al}$ atoms into the inner part of the specimen. Therefore, the graded structure in FGC-3 specimen seems to suppress the diffusion of Al into the substrate, resulting in high thermal stability of microstructure at elevated temperatures. In addition, in Pack-1 specimen, cracks penetrating the coated layer were sometimes found. An example of such a crack caused by thermal stress is shown in Fig. 6(e). Hence, the functionally graded coating layer is believed to work well for avoiding thermal cracking.

\section{Discussions}

\subsection{Microstructural Evolution during the Powder- Liquid Coating Procedures}

To discuss the mechanism of the powder-liquid coating, pure iron specimens pasted with $\mathrm{FeAl}_{3}$ powder were heat- 

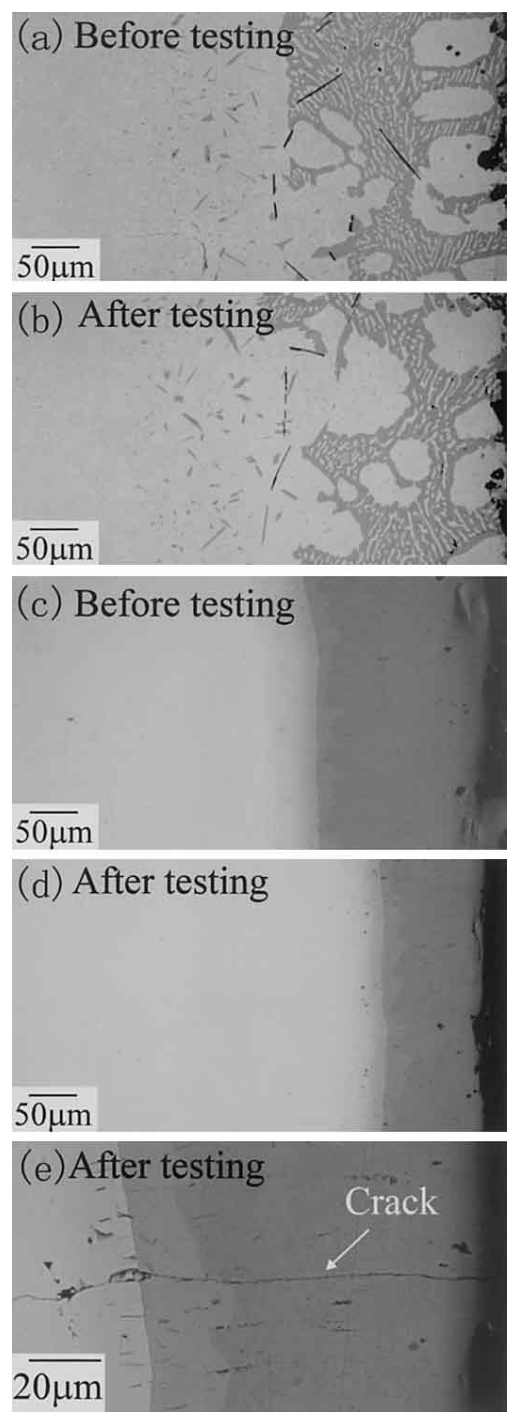

Fig. 6. SEM microstructures of FGC-3 specimen (a), (b) and Pack-1 specimen (c), (d), (e) before and after 200 times of repeated heating to $873 \mathrm{~K}$ and cooling, respectively.

ed up to $1473 \mathrm{~K}$, held there for $60,90,180$ or $300 \mathrm{~s}$ and then quenched into water. The microstructures of the cross sections of the quenched specimens were observed with SEM and typical examples obtained from three different locations are presented in Fig. 7. The microstructural evolution was different from place to place. For the specimen held for $60 \mathrm{~s}$, the coated layer was partially peeled from the substrate during quenching as seen in Fig. 7(a). Here, the powder was partially melted but the diffusion reaction between $\mathrm{FeAl}_{3}$ powder and the Fe substrate did not take place significantly. In Fig. 7(b), the substrate was almost coated with intermetallic compounds. As illustrated in Fig. 8, the dominant phase of the coated layer is considered to be $\varepsilon$ phase at elevated temperatures through reaction diffusion, although $\mathrm{Al}$ concentration decreases with increasing the distance from the surface. At the same time, the averaged Al concentration in the coated layer is considered to decrease with increasing of holding time. For instance, if the chemical composition corresponds to point $\mathrm{p}$ in Fig. 8(a), $\mathrm{FeAl}_{2}$ would precipitate and the remaining $\varepsilon$ phase would transform to the $\mathrm{FeAl} / \mathrm{FeAl}_{2}$ eutectoid structure (see I to IV in Figs. 8(a) and 8(b), the resultant microstructure was schematically drawn in a bottom figure at the right hand
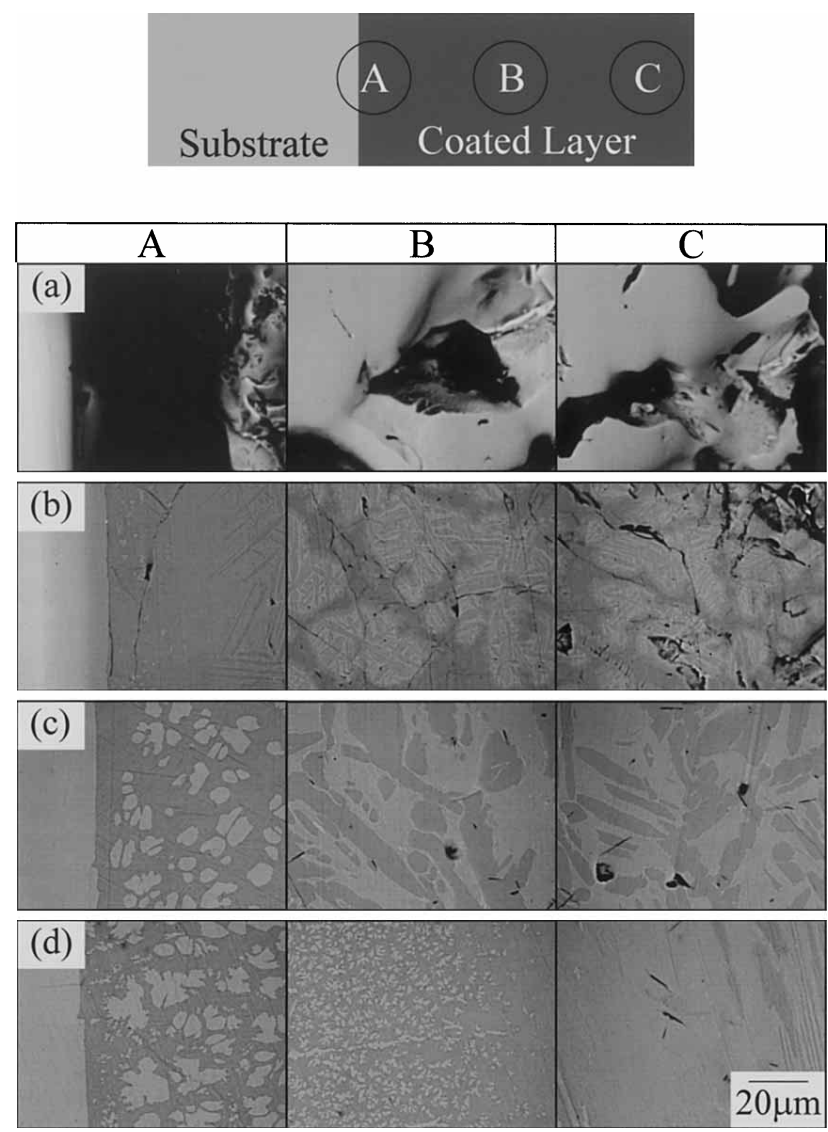

Fig. 7. Changes in the microstructure during coating heat treatment for FGC-1 specimen. Four samples were quenched into water after holding at $1473 \mathrm{~K}$ for $60 \mathrm{~s}$ (a), $90 \mathrm{~s}$ (b), $180 \mathrm{~s} \mathrm{(c)} \mathrm{and} 300 \mathrm{~s}$ (d), respectively. Typical three locations of their cross sections, A, B and C as indicated in a top figure were observed by SEM with BEI mode.

side of (b)). Such a microstructure is found in B and C of Fig. 7(c). On the other hand, at a place whose chemical composition is shown by point $\mathrm{q}$ in Fig. 8, FeAl would precipitate as a primary phase during cooling and the remaining coated layer would change to the $\mathrm{FeAl} / \mathrm{FeAl}_{2}$ eutectoid structure (see the left hand side of Fig. 8(b)). This must be the case of A and B of Fig. 7(d). As is expected from Fig. 8, the microstructure can be controlled by the Al concentration of the coating layer, which can be altered by the heating and cooling program of the powder-liquid coating procedures.

\subsection{Comparison of the Functionally Graded Coating with the Conventional Coating}

As described in section 3.5, the present coating layer is found to have higher resistance to thermal shock than the conventional aluminizing coating layer. This excellent property must have resulted from the functionally graded structure. Another finding to be noted here is the mechanical properties of the $\mathrm{FeAl} / \mathrm{FeAl}_{2}$ eutectoid structure. The hardness of $\mathrm{FeAl}_{3}$ obtained without visible cracking by using a load of $50 \mathrm{~g}$ was $824 \mathrm{HV}$ while the eutectoid structure $\mathrm{FeAl} / \mathrm{FeAl}_{2}$ was $927 \mathrm{HV}$. Examples of indentation made by a Vickers hardness tester with a larger load of $300 \mathrm{~g}$ in the coated layers of FGC-3 and Pack-1 specimens are shown in Fig. 9. As seen in (a), the $\mathrm{FeAl} / \mathrm{FeAl}_{2}$ eutectoid structure shows high hardness and high ductility, where nei- 
(a)

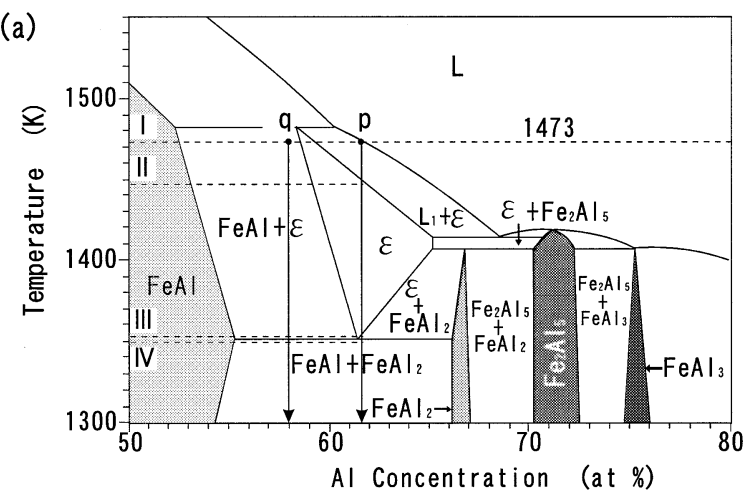

(b)

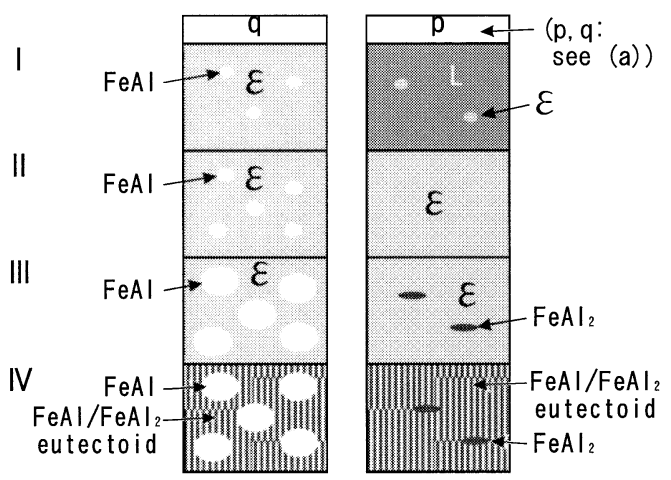

Fig. 8. Schematic illustrations to explain changes in the microstructures observed in Fig. 7: (a) a part of the $\mathrm{Fe}-\mathrm{Al}$ phase diagram schematically drawn after Ref. 7) and (b) illustrations to explain microstructural changes during cooling.

ther cracking nor detachment was observed around the indentation in FGC-3 specimen. Contrary to this, $\mathrm{FeAl}_{3}$ was so brittle that many cracks and detachments were found in the vicinity of the Vickers indentation in Pack-1 specimen as observed in Fig. 9(b). Although aluminides are very brittle in general, ${ }^{1)}$ the $\mathrm{FeAl} / \mathrm{FeAl}_{2}$ eutectoid structure seems to show relatively high toughness.

The drawback of the present coating method is that the coating temperature is higher than the conventional method. Grain growth may become a problem for steels which require high strength and high toughness. In the case of the present $\mathrm{S} 45 \mathrm{C}$ substrate, the prior austenite grain size was approximately $200 \mu \mathrm{m}$ after the coating. Some trials may be examined to overcome this weak point. For instance, to heat only the surface region using induction coils or laser beam may be hopeful. In the case of steels that are used after quenching and tempering, so called Grange method ${ }^{12)}$ is applicable as will be described in the next section.

\subsection{Grain Refinement of the S45C Substrate after the Coating}

In the case of a martensite steel, cyclic rapid heating and quenching from a temperature in the austenite stable region can be utilized for grain refinement because the coated layer is strong enough to thermal shock. When the coated specimens was quenched from $1173 \mathrm{~K}$ repeatedly, the prior austenite grain size (ASTM grain size) of about $200 \mu \mathrm{m}$ after the coating reduced to $40 \mu \mathrm{m}$ after the second quenching and below $10 \mu \mathrm{m}$ after the third quenching.
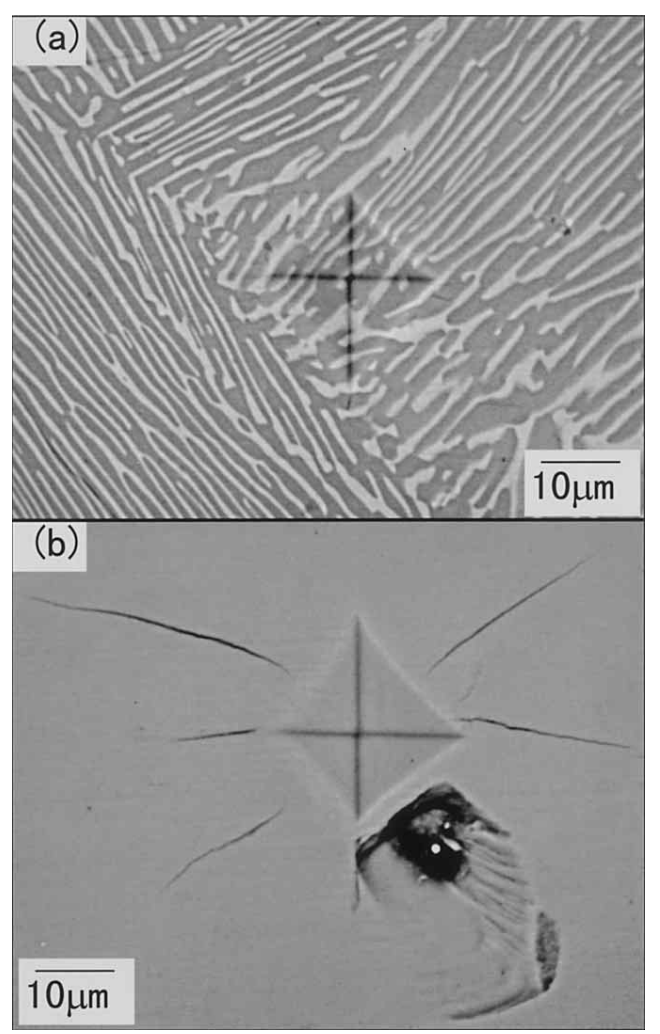

Fig. 9. SEM micrographs of indentation made by a Vickers hardness tester with a load of $300 \mathrm{~g}$ in FGC-3 specimen (a) and Pack-1 specimen (b).

\section{Conclusions}

A commercial pure iron and a carbon steel (JIS-S45C) were coated with $\mathrm{FeAl}_{3}$ powder by using the powder liquid coating method. The microstrucrural evolution during the coating treatment was studied and some properties of the coated specimens were examined. The main results obtained are summarized as follows.

(1) Functionally graded coating can be obtainable for plate substrates made of pure iron or S45C by using the powder liquid coating technique, where the plates coated with $\mathrm{FeAl}_{3}$ powder are heated up to $1473 \mathrm{~K}$, held there for $300 \mathrm{~s}$ and then cooled to room temperature. This technique is applicable to a semi-round bar specimen.

(2) The coated layers exhibit gradual change not only in the chemical compositions but also in the microstructure and hardness.

(3) The outer region of the coated layer consists of $\mathrm{FeAl}$ and $\mathrm{FeAl} / \mathrm{FeAl}_{2}$ eutectoid structure which is suggested to show relatively high strength and high toughness from the results of hardness test.

(4) The coated specimens show high resistance to thermal shock compared with the conventional aluminizing method. Neither cracking nor peeling-off was observed in the specimens coated by the present method when they were subjected to cyclic heating and cooling between room temperature and $873 \mathrm{~K}$.

(5) Because the coated layer is so stable during heating and cooling cycles, repeated quenching, so called Grange method, can be employed to refine the prior austenite grain size for S45C substrates. 


\section{Acknowledgements}

The present investigation was financially supported by ISIJ Research Promotion Grant (Iron and Steel Inst. Japan). We are grateful to Prof. T. Tsujimoto for his valuable advice and Dr. T. Suzuki and Mr. H. Sato for their experimental assistance.

\section{REFERENCES}

1) For example, N. S. Stoloff: Mater. Sci. Eng., A258 (1988), 1.

2) H. Tominaga and S. Ueda: J. Met. Finish. Soc. Jpn., 26 (1975), 20.

3) S. Kirihara, Y. Tomota and T. Tsujimoto: Mater. Sci. Eng., A239 (1997), 600.

4) Y. Tsucihda, S. Kirihara, Y. Tomota and T. Tsujimoto: J. Jpn. Inst.
Met., 62 (1998), 992.

5) I. Suzuki, S. Kirihara, T. Suzuki and T. Tsujimoto: Proc. $9^{\text {th }}$ Symp. on Functionally Graded Materials, The Society of Non-Traditional Technology, Tokyo, (1997), 39.

6) S. Kirihara: J. Jpn. Inst. Light Met., 49 (1999) 458.

7) Binary Alloys Phase Diagrams, ASM, Metals Park, OH, (1990), 147.

8) T. Shitase, K. Mori and K. Inoue: J. Met. Finish. Soc. Jpn., 17, (1966), 310.

9) T. Suzuki, T. Takano, I. Suzuki and Y. Tomota: J. Jpn. Inst. Light Met., 47 (1997), 685.

10) M. Chigasaki: Ph. D Thesis, Kyoto University, (1986), 98.

11) V. K. Sikka, R. H. Baldwin and C. R. Howell: ORNL/TN 378316083, 197.

12) R. A. Grange: Trans. Am. Soc. Met., 59 (1966), 26. 